\title{
Concomitant Nevirapine Therapy is Associated with Higher Efficacy of Pegylated Interferon Plus Ribavirin among HIV/ Hepatitis C Virus-Coinfected Patients
}

José A. Mira ${ }^{1,2}$, Luis F. López-Cortés ${ }^{3}$, Eugenia Vispo4, Cristina Tural ${ }^{5}$, Montserrat Laguno 6 , Elena Ferrer ${ }^{7}$, Ignacio de los Santos-Gil 8 , Pere Domingo $^{9}$, Hernando Knobel ${ }^{10}$, Francisco Téllez ${ }^{11}$, Manuel Crespo ${ }^{12}$, Antonio Rivero ${ }^{13}$, Enrique Ortega ${ }^{14}$ and Juan A. Pineda ${ }^{2 \star}$ on behalf of the VIRA-C Study Group ${ }^{a}$

${ }^{1}$ Servicio de Medicina Interna, Hospital Universitario de Valme, Sevilla, Spain

2Unidad de Enfermedades Infecciosas, Hospital Universitario de Valme, Sevilla, Spain

${ }^{3}$ Servicio de Enfermedades Infecciosas, Hospitales Universitarios Virgen del Rocío, Sevilla, Spain

${ }^{4}$ Servicio de Enfermedades Infecciosas, Hospital Carlos III, Madrid, Spain

${ }^{5}$ Unidad Clínica de VIH, Servicio de Medicina Interna, Hospital Universitario Germans Trias i Pujol, Barcelona, Spain

${ }^{6}$ Servicio de Enfermedades Infecciosas, Hospital Clinic, Barcelona, Spain

${ }^{7}$ Servicio de Enfermedades Infecciosas, Hospital Universitario de Bellvitge, L'Hospitalet, Barcelona, Spain

${ }^{8}$ Servicio de Medicina Interna-Enfermedades Infecciosas, Hospital Universitario de la Princesa, Madrid, Spain

${ }^{9}$ Unidad de Enfermedades Infecciosas, Hospital de la Santa Creu i Sant Pau, Barcelona, Spain

${ }^{10}$ Servicio de Medicina Interna-Enfermedades Infecciosas, Hospital del Mar, Barcelona, Spain

${ }^{11}$ Servicio de Medicina Interna, Hospital de la Línea de la Concepción, Cádiz, Spain

${ }^{12}$ Servicio de Enfermedades Infecciosas, Hospital Universitario Vall d'Hebron, Barcelona, Spain

${ }^{13}$ Unidad de Enfermedades Infecciosas, Hospital Universitario Reina Sofía, Córdoba, Spain

${ }^{14}$ Unidad de Enfermedades Infecciosas, Hospital General Universitario, Valencia, Spain, Grupo HEPAVIR de la Sociedad Andaluza de Enfermedades Infecciosas (SAEI)

${ }^{a}$ Members of the VIRA-C study group are listed at the end of the text

\section{Abstract}

Objective: To determine the influence of nevirapine (NVP) and lopinavir/ritonavir (LPV/r) on the efficacy of pegylated interferon (peg-IFN) plus ribavirin (RBV) among HIV/HCV-coinfected patients.

Methods: All HIV/HCV-coinfected patients who received peg-IFN plus RBV while under a three-drug antiretrovira regimen including tenofovir (TDF) plus lamivudine (3TC) or emtricitabine (FTC) along with NVP or along with LPV/r at twenty hospitals in Spain were included in this retrospective study. Sustained virological response (SVR) rates in both groups were compared.

Results: A total of 165 patients were included in the study, 71 (43\%) receiving NVP and 94 (57\%) LPV/r. Significantly more patients on $\mathrm{LPV} / \mathrm{r}$ had a baseline HCV-RNA load $\geq 600000 \mathrm{IU} / \mathrm{mL}(44 \%$ vs. $73 \%, \mathrm{p}=0.001)$. Forty $(56 \%)$ individuals included in the NVP group and $35(37 \%)$ in the LPV/r group showed SVR ( $=0.015)$. In the NVP group, $19(43 \%)$ patients carrying genotype 1-4 and $21(78 \%)$ subjects with genotype 2-3 achieved SVR. In the LPV/r group, the corresponding figures were $25 \%(p=0.04)$ and $59 \%(p=0.1)$. In the subpopulation of individuals with baseline HCV viral load $\geq 600,000$ $\mathrm{IU} / \mathrm{mL}, 18(58 \%)$ of those taking NVP vs. $21(31 \%)$ who were given LPV/r reached SVR $(p=0.01)$. HCV genotype 2-3, adherence to HCV therapy $>80 \%$ and use of NVP during peg-IFN plus RBV were independently associated with SVR in the multivariate analysis.

Conclusions: HIV/HCV-coinfected patients who receive NVP respond better to peg-IFN plus RBV than those individuals receiving LPV/r. Lower HCV viral load due to NVP treatment may account for the former differences.

Keywords: HIV; Pegylated interferon; Ribavirin; Nevirapine; Lopinavir/ritonavir

\section{Introduction}

Concomitant antiretroviral therapy (ART) can be a factor leading to a lower efficacy of pegylated interferon (peg-IFN) plus ribavirin (RBV) in human immunodeficiency virus (HIV)/hepatitis C virus (HCV)-coinfected patients [1-8]. Some nucleoside retrotranscriptase inhibitors (NRTI) may decrease the tolerability of HCV therapy due to different interactions and toxicities, reducing the rate of success of such a therapy [1-8]. Thus, the administration of didanosine along with RBV is not recommended due to an increased risk of episodes of mitochondrial toxicity [3-5], whereas the use of stavudine might increase weight loss related to peg-IFN plus RBV treatment [2]. Zidovudine use is related to an increased frequency of severe anemia and RBV dose reduction $[1,3,4,6]$. Finally, the use of abacavir has been associated in some reports with a lower efficacy of therapy against HCV infection than combinations containing tenofovir (TDF) $[7,8]$. Accordingly, TDF plus lamivudine (3TC) or emtricitabine (FTC) is the first choice of NRTI combinations in coinfected individuals on treatment for HCV infection $[1,7]$.
However, there is currently little information about whether protease inhibitors (PI) and non-nucleoside reverse transcriptase inhibitors (NNRTI) influence the rate of sustained virological response (SVR) in HIV/HCV-coinfected individuals. The use of PIs during HCV therapy led to a worse rate of response to peg-IFN plus RBV in the Ribavic clinical trial [9], whereas this association was not found in

*Corresponding author: Dr. Juan A. Pineda, Servicio de Medicina Interna, Hospital Universitario de Valme, Sevilla, Spain, Tel: 955015864; Fax: 955015684 E-mail: japineda@telefonica.net

Received November 04, 2010; Accepted December 20, 2010; Published December 21, 2010

Citation: Mira JA, López-Cortés LF, Vispo E, Tural C, Laguno M, et al. (2010) Concomitant Nevirapine Therapy is Associated with Higher Efficacy of Pegylated Interferon Plus Ribavirin among HIV/Hepatitis C Virus-Coinfected Patients. J AIDS Clinic Res 1:112. doi:10.4172/2155-6113.1000112

Copyright: (C) 2010 Mira JA, et al. This is an open-access article distributed unde the terms of the Creative Commons Attribution License, which permits unrestricted use, distribution, and reproduction in any medium, provided the original author and source are credited. 
other trials and cohort studies performed in the HIV-coinfected population [1,10]. Nevertheless, the findings of these studies might have been confounded by the combination of NRTIs with PIs in different proportions $[1,9,10]$. On the other hand, the results observed in a recent study showed that nevirapine (NVP)-based ART is associated with lower plasma HCV viral load in HIV/HCV-coinfected patients [11]. This finding may have a positive impact on the response to HCV therapy among coinfected individuals receiving NVP during anti-HCV therapy.

Our hypothesis was that patients taking NVP may respond better to peg-IFN plus RBV than those receiving PIs. For this reason, we undertook the present study, aimed to compare the efficacy of pegIFN plus RBV combination among HIV/HCV-coinfected patients taking TDF plus FTC or 3TC along with NVP with that observed in individuals who receive TDF plus FTC or 3TC and lopinavir/ritonavir (LPV/r), one of the most commonly used PIs.

\section{Patients and Methods}

\section{Study population and follow-up}

All individuals seen from January 2002 through January 2009 in twenty hospitals from Spain, who fulfilled the following criteria, were included for this retrospective study: 1) Older than 18 years; 2) Diagnosed with HIV infection and chronic hepatitis C; 3) Started a first course of therapy against HCV infection with peg-IFN plus RBV treatment, and, 4) Were receiving a three-drug antiretroviral regimen containing TDF plus 3TC or FTC along with NVP or LPV/r when they began therapy against HCV infection. All subjects were followed-up at least every 4 weeks during the first 24 weeks of HCV therapy and every 8 to 12 weeks during the remaining treatment period. After peg-IFN plus RBV treatment completion, patients were followed-up for at least 24 weeks in order to assess SVR. Clinical, biochemical and hematological assessments were carried out at every visit.

Our study was designed to have a statistical power of 75\% (with a two-side alfa value of 0.05 ) to detect a difference in the SVR rate between both treatment groups of $20 \%$ (alternative hypothesis), assuming that $40 \%$ of patients would be on NVP and $60 \%$ on LPV/r. The minimum sample size calculated was 63 subjects for the NVP group and 93 individuals for the $\mathrm{LPV} / \mathrm{r}$ group.

\section{Treatment strategies}

All patients received the combination of peg-IFN alfa-2a at a dose of $180 \mu \mathrm{g}$ given once weekly or peg-IFN alfa-2b at a dose of $1.5 \mu \mathrm{g} / \mathrm{kg}$ given once weekly along with oral RBV at a dose of 800 to $1200 \mathrm{mg}$ per day. The length of the therapy was 48 weeks in all HCV genotype 1 or 4 carriers, whereas those individuals infected with HCV genotype 2 or 3 who reached rapid virologic response at week 4 received pegIFN plus RBV during 24 or 48 weeks, according to the decision of the treating physician. The remaining individuals with HCV genotype 2 or 3 were treated during 48 weeks. Dosage adjustments for pegIFN and RBV and the use of granulocyte colony-stimulating factor and erythropoietin were performed according to the criteria of the physician who was treating the patient. HCV therapy was discontinued in patients who were non-responders.

NVP was administered at a dosage of $200 \mathrm{mg}$ twice daily or 400 $\mathrm{mg}$ once daily according to the decision of the physician responsible for the patient. LPV/R was given twice a day at a dosage of $400 \mathrm{mg} / 100$ $\mathrm{mg}$ or once a day at a dosage of $800 \mathrm{mg} / 200 \mathrm{mg}$, either as soft-gel capsule, before December 2006, or as film coated tablets thereafter.

\section{Assessment of efficacy}

The primary variable of the study was SVR, defined as an undetectable plasma HCV-RNA six months after the end of peg-IFN plus RBV treatment. End of treatment response (ETR) was defined as undetectable plasma HCV-RNA at completion of therapy at week 24 or 48 . A patient was considered to have developed early virologic response (EVR) when HCV-RNA levels had declined at least a $2 \log _{10}$ or had become undetectable at week 12 . Individuals who did not reach at least $2 \log _{10}$ reduction in HCV-RNA levels at week 12 of treatment or undetectable plasma HCV-RNA at week 24 were considered as non-responders. Virological breakthrough was defined as detectable plasma HCV-RNA after week 24 of therapy in patients with previous undetectable HCV viral load. Relapse was defined as lack of SVR after having reached ETR. Two sensitivity analyses were performed for estimating the efficacy: The first one was carried out according the principle of intention to treat, considering all non-completers or antiretroviral regimens with switches as failures. The second one was a per-protocol analysis.

\section{Laboratory methods}

Measurements of plasma HCV-RNA load were performed at baseline and at least at 12, 24 and 48 weeks during HCV therapy and 24 weeks after stopping therapy. Plasma HCV-RNA load was measured using a quantitative polymerase chain reaction assay according to the available technique at each time (Cobas Amplicor HCV Monitor; Roche Diagnostic Systems Inc., Branchburg, NJ, USA: detection limit of $600 \mathrm{IU} / \mathrm{mL}$; Cobas AmpliPrep-Cobas TaqMan; Roche Diagnostic Systems Inc., Meylan, France: detection limit of $50 \mathrm{IU} / \mathrm{mL}$; Cobas TaqMan; Roche Diagnostic Systems Inc., Pleasanton, CA, USA: detection limit of $10 \mathrm{IU} / \mathrm{mL}$ ).

\section{Statistical analysis}

The association between SVR and the use of NVP- or LPV/r-based ART during the course of HCV therapy was analyzed. Likewise, we assessed the relationship between SVR rate and the following variables: age, sex, body mass index, risk factor for HCV transmission, HCV genotype, baseline plasma HCV-RNA load, baseline plasma level of alanine aminotransferase and low-density lipoprotein cholesterol, CDC clinical category, CD4+ cell count and HIV-RNA at baseline, liver fibrosis stage according to the Scheuer's scoring system [12] in patients who had had a pretreatment liver biopsy, type of peg-IFN given, daily dose of RBV by weight, participating center, calendar year of beginning anti-HCV therapy, self-reported compliance with therapy, time with undetectable HIV viral load before starting HCV therapy and time from starting NVP or LPV/r to beginning therapy against HCV infection.

Categorical variables are expressed as numbers (percentages) and continuous variables are expressed as median values [interquartile range $(\mathrm{Q} 1-\mathrm{Q} 3)]$. The frequencies were compared using the chisquare test or the Fisher's test, if the expected frequency for any cell was five or lower. The Student's $t$-test was used for comparisons between continuous variables if a normal distribution was followed and the Mann-Whitney $U$ test if not. Variables associated with SVR in the univariate analysis with a $\mathrm{p}$ value $<0.1$ were entered in logistic regression models. Associations with $\mathrm{p}<0.05$ were considered significant. The adjusted odds ratio (AOR) and the respective $95 \% \mathrm{CI}$ were also calculated. The goodness-of-fit of the models was assessed by the Hosmer-Lemeshow test. The results of the best fitted model were chosen. The Pearson $r$ coefficient was used to examine the correlation between the levels of HCV viremia and the length of 
time with undetectable HIV viral load before starting HCV therapy. The statistical analysis and the sample size calculations were carried out using the SPSS statistical software package release 15.0 (SPSS Inc., Chicago, IL, USA) and the PS program version 3.0 (Vanderbilt Biostatistics, Nashville, TN, USA), respectively.

\section{Ethical aspects}

The study was designed and performed according to the Helsinki declaration and was approved by the Ethics Committee of the Autonomous Region of Andalusia (Spain).

\section{Results}

\section{Characteristics of the study population}

One hundred and sixty-five patients fulfilled the inclusion criteria (Figure 1). A total of 71 (43\%) individuals were treated with NVP and 94 (57\%) subjects with LPV/r. Forty-four (61\%) individuals taking NVP harbored HCV genotype 1 or 4 vs $60(64 \%)$ out of those who received $\mathrm{LPV} / \mathrm{r}$-based ART $(\mathrm{p}=0.7)$. At the beginning of therapy against HCV infection, the median HCV-RNA level in the NVP group was 5.7 (interquartile range, 5.3-6.3) $\log _{10} \mathrm{IU} / \mathrm{mL}$ and 6.1 (interquartile range, 5.6-6.5) $\log _{10} \mathrm{IU} / \mathrm{mL}$ in the $\mathrm{LPV} / \mathrm{r}$ group $(\mathrm{p}=0.02)$. The levels of HCV viremia at baseline did not correlate with time showing undetectable HIV viral load before starting HCV therapy $(r=0.06, \mathrm{p}=0.4)$. Among those individuals who had undergone a liver biopsy, $10(21 \%)$ subjects receiving NVP showed liver fibrosis stage $F \geq 3$ at baseline compared to $36(52 \%)$ of those who were treated with $\mathrm{LPV} / \mathrm{r}(\mathrm{p}=0.001)$. The remaining relevant characteristics of the patients included in the study appear in table 1 . NVP and LPV/r were not discontinued in any individual during HCV therapy.

\section{Response to HCV therapy}

In the intention-to-treat analysis, 97 (59\%) individuals showed ETR and 75 (45\%) patients reached SVR in the entire population. Forty (56\%) patients treated with NVP showed SVR compared to $35(37 \%)$ of those receiving LPV/r [difference: $19 \%$; $95 \% \mathrm{CI}: 4 \%-34 \% ; \mathrm{p}=0.015$ ]. For genotype 1 or 4,19 (43\%) patients in the NVP group and $15(25 \%)$ in the LPV/r group achieved SVR [difference: $18 \%$; $95 \% \mathrm{CI}: 1.3 \%-36 \%$; $\mathrm{p}=0.04]$. Among the group of subjects with HCV genotype 2 or 3,21 (78\%) of those taking NVP vs. 20 (59\%) who were given LPV/r reached SVR [difference: $19 \%$; $95 \% \mathrm{Cl}:-7 \%-41 \% ; \mathrm{p}=0.1$ ]. In the subpopulation of individuals receiving a NRTI backbone containing TDF plus FTC, 17 (65\%) patients receiving NVP-based ART showed SVR compared with $14(40 \%)$ of those who received combinations of $L P V / r(p=0.05)$. The rates of ETR and EVR according to the type of antiretroviral given are shown in (Figure 2)

In the intention-to-treat analysis, $6(8 \%)$ patients included in the NVP group and $22(23 \%)$ in the LPV/r group were non-responders $(p=0.01)$. The differences in the frequencies of other types of response to peg-IFN plus RBV treatment between NVP and LPV/r group, including virological breakthrough, relapse, withdrawal due to adverse events and voluntary drop out, were not significant in the statistical analysis (Figure 3). The dose of peg-IFN or RBV had to be temporally or permanently reduced in $18(25 \%)$ patients who were treated with NVP-based ART and in $19(20 \%)$ subjects receiving LPV/rbased ART $(p=0.4)$. The frequency of use of growth factors during anti-HCV therapy was similar in both treatment groups (Table 1).

Because the arms were unbalanced regarding potential predictors of SVR, the response to peg-IFN plus RBV treatment stratifying the population according to these parameters was analyzed by intention- to-treat analysis (Table 2). In the subpopulation of individuals with baseline levels of plasma HCV viral load equal or higher than 600,000 $\mathrm{IU} / \mathrm{mL}, 18$ (58\%) patients who were receiving NVP and 21 (31\%) taking $L P V / r$ reached SVR $(p=0.01)$. Among those individuals with liver fibrosis stage $F \geq 3$ at baseline, $6(60 \%)$ subjects included in the NVP group and $13(36 \%)$ patients in the $L P V / r$ group showed SVR $(p=0.2)$.

Among the 143 patients included in the per-protocol analysis, 40 (63\%) individuals who were treated with NVP showed SVR compared with $35(44 \%)$ patients taking LPV/r-based ART $(\mathrm{p}=0.019)$. In the subgroup of patients with HCV genotype 1 or 4 , the rates of SVR in
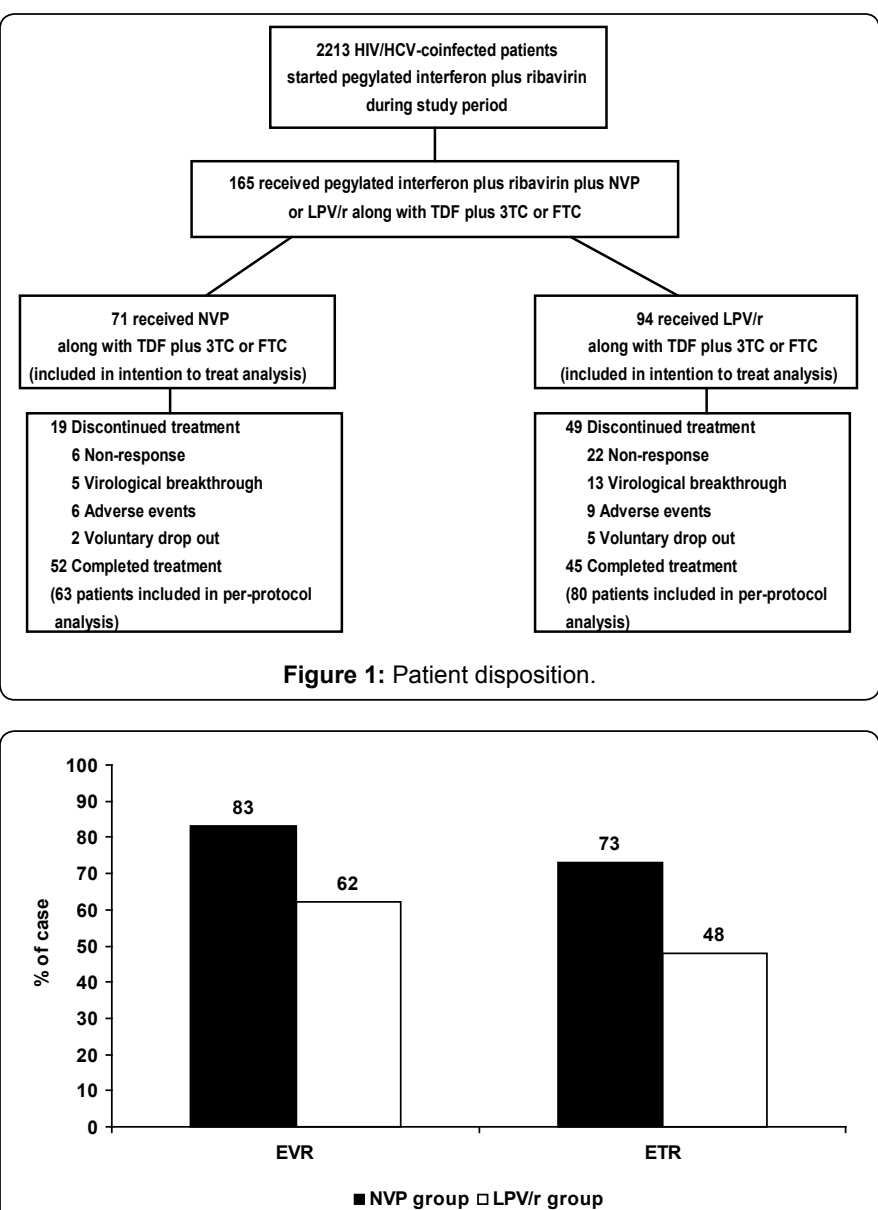

Figure 2: Rates of early virologic response (EVR) and end of treatment response (ETR) in patients included in the two arms (intention-to-treat analysis).

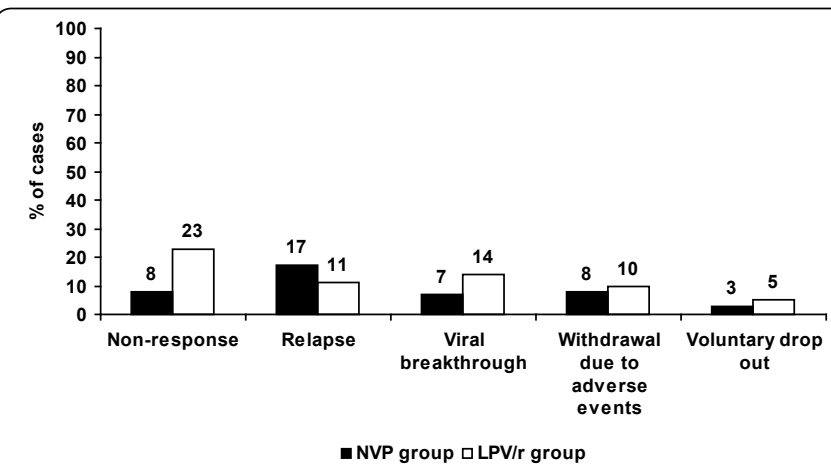

Figure 3: Causes of lack of sustained virological response to pegylated interferon plus ribavirin combination in both arms (intention-to-treat analysis). 


\begin{tabular}{|c|c|c|c|}
\hline Variables & NVP group $n=71$ & LPV/r group $n=94$ & $\mathbf{p}$ \\
\hline Age (years)* & $42(38-45)$ & $41(37-44)$ & 0.2 \\
\hline Male gender no. (\%) & $47(66)$ & $76(81)$ & 0.03 \\
\hline Body mass index $\left(\mathrm{Kg} / \mathrm{m}^{2}\right)^{*}$ & $22.8(20.5-24.4)$ & $23.2(21.7-24.9)$ & 0.5 \\
\hline \multicolumn{4}{|l|}{ HCV infection } \\
\hline Former IDU no. (\%) & $55(76)$ & $81(86)$ & 0.1 \\
\hline Baseline HCV-RNA <600000 IU/mL no. (\%) & $40(56)$ & $25(27)$ & 0.001 \\
\hline Cirrhosis no. $(\%)^{\dagger}$ & $3(6)$ & $22(32)$ & 0.001 \\
\hline Baseline serum ALT (IU/L)* & $71(45-100)$ & $69(45-100)$ & 0.8 \\
\hline HCV genotype no. (\%) & & & 0.8 \\
\hline 1 & $32(45)$ & $47(50)$ & \\
\hline 2 & $1(1)$ & $2(2)$ & \\
\hline 3 & $26(37)$ & $32(34)$ & \\
\hline 4 & $12(17)$ & $13(14)$ & \\
\hline \multicolumn{4}{|l|}{ HCV therapy } \\
\hline Use of peg-IFN alfa-2a no. (\%) & $52(73)$ & $78(83)$ & 0.1 \\
\hline RBV dose/weight (mg/Kg/day)* & $15.3(13.8-16.4)$ & $14.5(13.4-16.1)$ & 0.1 \\
\hline Starting HCV therapy from 2000 to 2004 no. (\%) & $25(35)$ & $26(28)$ & 0.3 \\
\hline Peg-IFN plus RBV during 24 weeks no. (\%) & $11(15)$ & $10(11)$ & 0.3 \\
\hline Time from starting NVP or LPV/r to beginning HCV therapy (months) ${ }^{*}$ & $39(26-66)$ & $20(10-29)$ & 0.001 \\
\hline Compliance with HCV therapy $\geq 80 \%$ no. (\%) & $65(91)$ & $83(88)$ & 0.5 \\
\hline Use of growth factors no. (\%) & $3(4)$ & $10(11)$ & 0.1 \\
\hline \multicolumn{4}{|l|}{ HIV infection } \\
\hline CDC C Clinical category no. (\%) & $14(20)$ & $32(34)$ & 0.04 \\
\hline Time with undetectable HIV viral load before starting HCV therapy (months)* & $62(29-84)$ & $24(14-58)$ & 0.002 \\
\hline Baseline CD4 cell counts $/ \mathrm{mm}^{3 *}$ & $489(338-658)$ & $445(300-589)$ & 0.3 \\
\hline Baseline undetectable HIV viral load, no. (\%) & $68(95)$ & $77(82)$ & 0.007 \\
\hline Baseline LDL-cholesterol $(\mathrm{mg} / \mathrm{dL})^{\star}$ & $100(85-122)$ & $84(70-109)$ & 0.07 \\
\hline Use of FTC no. (\%) & $26(37)$ & $35(37)$ & 0.9 \\
\hline
\end{tabular}

*Median (Q1-Q3); ${ }^{\dagger}$ Liver biopsy was available in 47 individuals in the nevirapine (NVP) group and in 69 subjects in the lopinavir/ritonavir (LPV/r) group. IDU: intravenous drug user. ALT: alanine aminotransferase. peg-IFN: pegylated interferon. RBV: ribavirin. LDL: low-density lipoprotein. FTC: emtricitabine.

Table 1: Main features of both treatment groups.

\begin{tabular}{|c|c|c|c|}
\hline Variable & NVP group SVR /no. (\%) & LPV/r group SVR/no. (\%) & p univariate \\
\hline \multicolumn{4}{|l|}{ Baseline HCV RNA level } \\
\hline$>600000 \mathrm{IU} / \mathrm{mL}$ & $18 / 31(58)$ & $21 / 68(31)$ & 0.01 \\
\hline$<600000 \mathrm{IU} / \mathrm{mL}$ & $22 / 40(55)$ & $14 / 26(53)$ & 0.8 \\
\hline \multicolumn{4}{|l|}{ Liver fibrosis } \\
\hline Advanced (F3-F4) & $6 / 10(60)$ & $13 / 36(36)$ & 0.2 \\
\hline Non-advanced (F0-F2) & $18 / 37(47)$ & $11 / 33(33)$ & 0.2 \\
\hline \multicolumn{4}{|l|}{ Cirrhosis } \\
\hline Yes & $3 / 3(100)$ & $8 / 22(36)$ & 0.07 \\
\hline No & $21 / 44(47)$ & $16 / 47(34)$ & 0.2 \\
\hline \multicolumn{4}{|c|}{ Baseline LDL-cholesterol } \\
\hline$>100 \mathrm{mg} / \mathrm{dL}$ & $16 / 25(64)$ & $10 / 23(43)$ & 0.1 \\
\hline$<100 \mathrm{mg} / \mathrm{dL}$ & $14 / 25(56)$ & $15 / 47(32)$ & 0.04 \\
\hline \multicolumn{4}{|c|}{ Baseline undetectable HIV viral load } \\
\hline Yes & $39 / 68(57)$ & $30 / 77(39)$ & 0.02 \\
\hline No & $1 / 3(33)$ & $5 / 17(29)$ & 0.9 \\
\hline \multicolumn{4}{|c|}{ Time from starting NVP or LPV/r to beginning HCV therapy ${ }^{\dagger}$} \\
\hline$<27$ months & $14 / 25(56)$ & $21 / 57(36)$ & 0.05 \\
\hline$>27$ months & $26 / 46(56)$ & $14 / 37(37)$ & 0.05 \\
\hline \multicolumn{4}{|c|}{ Time with undetectable HIV viral load before starting HCV therapy ${ }^{{ }^{*}}$} \\
\hline$<42$ months & 19/26 (73) & $17 / 44(39)$ & 0.009 \\
\hline$>42$ months & $21 / 42(50)$ & $12 / 33(37)$ & 0.2 \\
\hline
\end{tabular}

${ }^{\dagger}$ Categorized by median. ${ }^{*}$ Excluding patients with detectable HIV viral load at baseline. NVP: nevirapine. LPV/r: lopinavir/ritonavir.

Table 2: Sustained virologic response (SVR) in both treatment groups according to different variables.

the NVP and $\mathrm{LPV} / \mathrm{r}$ group were $50 \%$ and $31 \%$, respectively $(\mathrm{p}=0.06)$. For HCV genotypes 2 or 3 , SVR rates were $87 \%$ in the NVP group and $64 \%$ among combinations containing $\mathrm{LPV} / \mathrm{r}(\mathrm{p}=0.05)$.

\section{Predictors of sustained virologic response}

In the entire cohort, median time showing undetectable HIV viral load before starting HCV therapy among patients with SVR was 39.1 (interquartile range, 19.0-69.8) months and 45.7 (interquartile range, 18.9-64) months in those without SVR $(\mathrm{p}=0.8)$. The median time from starting NVP or LPV/r to beginning peg-IFN plus RBV treatment among individuals with SVR was 27 (interquartile range, 10-45) months and 26 (interquartile range, 12-40) months in those subjects without SVR $(\mathrm{p}=0.4)$.

HCV genotype 2 or 3 , an exposure to the HCV therapy greater than $80 \%$ of the planned dose and use of ART containing TDF plus 3TC or FTC along with NVP were independent predictors of SVR in the multivariate analysis (Table 3). In this model, an interaction between NVP- or LPV/r-treatment and plasma HCV viral load at baseline was observed [AOR 1.2, 95\% CI 1.05-1.3; $\mathrm{p}=0.005$ ]. When we performed the multivariate analysis excluding the use of NVP- or LPV/r-based ART during HCV therapy, lower baseline plasma HCV-RNA load [AOR 2.0, 95\% CI 1.05-3.3; $\mathrm{p}=0.03$ ] was associated with SVR. The participant hospital was not associated with SVR.

\section{Discussion}

In this study, HIV/HCV-coinfected patients who were treated with a three-drug regimen including TDF plus 3TC or FTC along with NVP responded better to peg-IFN plus RBV than those who took $L P V / r$, a finding that has not been previously reported. The positive impact of NVP on the SVR rate was also observed among coinfected individuals with known predictors of poorer response to HCV therapy, such as genotypes 1 or 4 and high HCV RNA load at baseline. 
Citation: Mira JA, López-Cortés LF, Vispo E, Tural C, Laguno M, et al. (2010) Concomitant Nevirapine Therapy is Associated with Higher Efficacy of Pegylated Interferon Plus Ribavirin among HIV/Hepatitis C Virus-Coinfected Patients. J AIDS Clinic Res 1:112. doi:10.4172/2155-6113.1000112

Page 5 of 8

This is the first study, to our knowledge, in which the influence of NVP and LPV/r has been specifically assessed in HIV/HCV-coinfected patients receiving therapy against $\mathrm{HCV}$. The rate of SVR observed in the present study among individuals taking NVP is in the range previously reported in clinical trials in the HCV-monoinfected population [13-15], whereas those subjects who received $\mathrm{LPV} / \mathrm{r}$ showed rates of response similar to those found in HIV/HCV-coinfected patients $[1,9,16-18]$. In our opinion, a different influence of NVP- and PI-based ART on HCV viral load could explain why individuals treated with NVP respond better than those receiving other antiretroviral drugs, such as LPV-r. Regarding this, it has been recently reported that individuals under NVP-containing regimens have lower HCV-RNA levels than those who are taking EFV- or PIs-based ART [11]. Previously, a study had also provided data showing that PI-based ART is associated with higher HCV viral load in the HIV-infected population [19]. These findings are very important, since a lower HCV viral load when starting HCV therapy is a strong predictor of SVR to peg-IFN plus RBV among coinfected individuals $[1,9,16,20]$. The results of the current study agree with above-mentioned studies, given that plasma HCV viral load below $600,000 \mathrm{IU} / \mathrm{mL}$ at baseline was twice as common among those patients who were treated with NVP. As HCV-RNA levels are lower in the HCV-monoinfected population [21], NVP use seems to make the HIV-infected patient similar to HCV-monoinfected subjects in terms of HCV viral load and, consequently, in SVR rate. Likewise, the fact that plasma HCV viral load at baseline was not associated with SVR in the multivariate analysis, when NVP- or LPV/r-based ART was included

\begin{tabular}{|c|c|c|c|c|}
\hline Variables & SVR no. (\%) & p univariate & Adjusted OR $(95 \% \mathrm{Cl})$ & P multivariate \\
\hline \multicolumn{5}{|l|}{ Age years) $^{\dagger}$} \\
\hline$<41$ & $34(44)$ & & & \\
\hline$\geq 41$ & $41(47)$ & 0.7 & - & - \\
\hline \multicolumn{5}{|l|}{ Gender } \\
\hline Male & $55(45)$ & & & \\
\hline Female & $20(48)$ & 0.7 & - & - \\
\hline \multicolumn{5}{|c|}{ Body mass index ${ }^{\dagger}$} \\
\hline$\leq 23$ & $28(48)$ & 0.3 & & \\
\hline$>23$ & $25(40)$ & & - & - \\
\hline \multicolumn{5}{|l|}{ Baseline $\mathrm{ALT}^{\dagger}$} \\
\hline$\leq 81$ & $40(43)$ & & & \\
\hline$>81$ & $35(49)$ & 0.4 & - & - \\
\hline \multicolumn{5}{|c|}{ Injecting drug user } \\
\hline Yes & $60(44)$ & & & \\
\hline No & $15(52)$ & 0.4 & - & - \\
\hline \multicolumn{5}{|c|}{ CDC clinical category } \\
\hline A-B & $59(50)$ & 0.08 & $1.7(0.7-3.9)$ & 0.1 \\
\hline $\mathrm{C}$ & $16(35)$ & & & \\
\hline \multicolumn{5}{|l|}{ Liver fibrosis } \\
\hline$\leq 2$ & $29(41)$ & & & \\
\hline$\geq 3$ & $19(41)$ & 0.9 & - & - \\
\hline \multicolumn{5}{|l|}{ Cirrhosis } \\
\hline Yes & $11(44)$ & 0.7 & - & - \\
\hline No & $37(41)$ & & & \\
\hline \multicolumn{5}{|l|}{ HCV genotype } \\
\hline $1-4$ & $34(33)$ & & & \\
\hline $2-3$ & $41(67)$ & $<0.001$ & $5.4(2.5-11.3)$ & $<0.001$ \\
\hline \multicolumn{5}{|c|}{ Baseline HCV-RNA load (IU/mL) } \\
\hline$<600000$ & $35(54)$ & 0.06 & $1.6(0.7-3.4)$ & 0.1 \\
\hline$\geq 600000$ & $39(39)$ & & & \\
\hline \multicolumn{5}{|c|}{ Daily dose of RBV $(\mathrm{mg} / \mathrm{kg})^{\dagger}$} \\
\hline$<14.8$ & $32(40)$ & & & \\
\hline$\geq 14.8$ & $39(48)$ & 0.3 & - & - \\
\hline \multicolumn{5}{|c|}{ Type of peg-IFN } \\
\hline Alfa-2a & $56(43)$ & & & \\
\hline Alfa-2b & $19(54)$ & 0.2 & - & - \\
\hline \multicolumn{5}{|c|}{ Initiation of peg-IFN treatment } \\
\hline 2001-2004 & $23(45)$ & & & \\
\hline $2005-2008$ & $52(46)$ & 0.9 & - & - \\
\hline \multicolumn{5}{|c|}{ Exposure to HCV therapy } \\
\hline$<80 \%$ & $4(23)$ & & & \\
\hline$\geq 80 \%$ & $71(48)$ & 0.05 & $4.8(1.3-17.8)$ & 0.01 \\
\hline \multicolumn{5}{|c|}{ Baseline undetectable plasma HIV-RNA } \\
\hline Yes & $69(48)$ & & & \\
\hline No & $6(30)$ & 0.1 & - & - \\
\hline \multicolumn{5}{|c|}{ Baseline CD4 cell count $/ \mathrm{mm}^{3 \dagger}$} \\
\hline$<459$ & $35(42)$ & & & \\
\hline$\geq 459$ & $40(49)$ & 0.4 & - & - \\
\hline Baseline CD4 & & & & \\
\hline$\geq 200$ & $71(45)$ & & & \\
\hline$<200$ & $4(50)$ & 0.8 & - & - \\
\hline Baseline LDL-C & & & & \\
\hline$\geq 100$ & $26(54)$ & & & \\
\hline$<100$ & $29(40)$ & 0.1 & - & - \\
\hline Third drug in $A$ & & & & \\
\hline NVP & $40(56)$ & 0.015 & $2.5(1.2-5.0)$ & 0.01 \\
\hline $\mathrm{LPV} / \mathrm{r}$ & $35(37)$ & & & \\
\hline NRTI backbon & & & & \\
\hline TDF plus 3TC & $44(42)$ & & & \\
\hline TDF plus FTC & $31(51)$ & 0.3 & - & - \\
\hline
\end{tabular}

${ }^{\dagger}$ Categorized by median. ALT: alanine aminotransferase. RBV: ribavirin. peg-IFN: pegylated interferon. LDL: low-density lipoprotein. ART: antiretroviral therapy. NVP: nevirapine. LPV/r: lopinavir/ritonavir. NRTIs: nucleos(t)ide retrotranscriptase inhibitors. TDF: tenofovir. 3TC: lamivudine. FTC: emtricitabine.

Table 3: Sustained virologic response (SVR) according to different variables in the entire cohort. 
in the models as covariate, suggest that both parameters are related. In fact, in this study, we found evidence of interaction between NVP use and baseline HCV viral load. Therefore, in our opinion, the use of NVP is a stronger predictor of response to HCV therapy in this population. Prospective studies are warranted in order to confirm the impact of NVP on HCV viral load in the HIV-infected population.

The possible mechanism whereby the use of NVP decreases HCV-RNA levels among HIV/HCV-infected patients is unknown. However, some data observed in recent studies could explain this finding. Lin and colleagues have reported that HIV can upregulate HCV replication through chemokine receptor-dependent means, and that this upregulation of HCV replication is mediated by transforming growth factor (TGF)- $\beta 1$ [22]. Likewise, it has been shown that the effect of NVP on proinflammatory cytokine levels is different to that found in HIV-infected patients receiving other antiretroviral drugs, such as efavirenz and abacavir [23]. For this reason, our hypothesis is that NVP use could lead to a greater reduction of proinflammatory cytokine levels, and secondarily, of TGF- $\beta 1$. Consequently, NVP use could be associated with lower levels of HCV replication in HIV-coinfected patients. On the other hand, immune and virologic recovery related to $A R T$ initiation is associated with a transient increase in HCV-RNA levels, followed by a continued decline [24]. Consequently, differences in HCV viral load and in SVR rate might have been driven by an unequal time on effective ART. To this effect, in our study, the time showing undetectable HIV viral load before starting peg-IFN plus RBV treatment was longer in the NVP group than in the LPV-r arm, which might have accounted for the differences in HCV-RNA levels and SVR rate between both groups. Nevertheless, there was no correlation between HCV-RNA level and duration of undetectable HIV viral load. Moreover, the time with undetectable HIV viral load before beginning HCV therapy was not associated with SVR in the univariate analysis. Finally, the rate of SVR was higher in patients taking NVP when the population was stratified according to the time on antiretroviral therapy and the time with undetectable HIV viral load. In our opinion, in vitro studies are required in order to determine the mechanism that explains the association between NVP use and low HCV viral load.

Besides the influence of NVP on HCV viral load, other potential mechanisms could explain the positive impact of NVP on the efficacy of peg-IFN plus RBV treatment. NVP-based ART is associated with lower insulin resistance [25], which has been shown in some reports to be a predictor of better response to HCV therapy in HCV-monoinfected patients $[26,27]$. Unfortunately, we did not have frozen serum samples available in order to determine insulin resistance and it is possible relationship with the rate of SVR in both treatment groups. However, recent studies have reported that insulin resistance is not a relevant predictor of SVR in the HIV-infected population [28-30], In addition, a specific and potent insulin resistance lowering agent do no provide significant benefits in the SVR rate when it is given along with pegIFN plus RBV [31]. All these data suggest that differences in insulin resistance should have not played an important role on the findings reported herein. On the other hand, although there are no specific studies on this topic, according to clinical and pharmacokinetic data regarding the pharmacokinetics of the drugs involved in this study, it seems unlikely that the development of drug interactions between NVP and peg-IFN or RBV could have had an impact on SVR.

This study has a main limitation: We cannot completely exclude that biases related to the retrospective and nonrandomized design might have an impact on the results found in this study. The proportion of patients with elevated levels of baseline plasma HCV-
RNA load and advanced liver fibrosis was higher among patients who received $L P V / r$ than in those subjects taking NVP, and both might have accounted for the differences in the rate of SVR between both arms. For this reason, only a randomized clinical trial could precisely determine how both drugs influence the rate of SVR in this population. However, clinical trials are currently difficult to undertake, because bitherapy with peg-IFN plus RBV will not likely be the standard of therapy for HCV infection in the next years. Nevertheless, some data lead us to believe that there should be no important biases in this study, and that the differences found here are real. With regards to the unequal levels of plasma HCV viral load, clinicians caring for the patients do not select ART depending on the level of plasma HCVRNA load in daily clinical practice. In addition, when we analyzed SVR rate stratifying the population according to baseline plasma HCVRNA load, differences in terms of SVR in both arms still remained, and patients with elevated baseline HCV-RNA load who were treated with NVP-containing regimens showed a significantly higher rate of SVR than those individuals receiving LPV/r. Conversely, although this issue is controversial, a potentially higher beneficial effect of PIs on fibrosis progression may influence the choice of ART in the HIVinfected population [32]. But, again, after stratifying the population according to liver fibrosis stage, the differences between NVP and $\mathrm{LPV} / \mathrm{r}$ remained similar. Thus, SVR rate in the subgroup of patients with liver fibrosis stage $\geq 3$ was greater in individuals under NVP. If significant differences were not reached when some subgroups were compared, it was likely due to a lack of statistical power, as this study was designed to compare the whole population.

This study supplies relevant information about the selection of the best antiretroviral combination in HIV/HCV-coinfected patients on treatment with peg-IFN plus RBV. Data regarding this issue are relevant, given that a proper choice of ART may enhance the chance of SVR [1-8]. According to the SVR rate observed in our study, a three-drug regimen including TDF plus 3TC or FTC along with NVP would be the best option in patients who are going to be treated against hepatitis $C$, especially in patients with predictors of poor response to HCV therapy. Nevertheless, NVP use as the first choice in this population has two main drawbacks. First, it is recommended that NVP should not be started in women with CD4 $>250$ cells $/ \mathrm{mm}^{3}$ or in men with CD4 $>400$ cells $/ \mathrm{mm}^{3}$, if another option is available due to an increased risk of treatment-limiting toxicities [33]. Many candidates for treatment with peg-IFN plus RBV have CD4 counts above this threshold. However, recent studies have reported that NVP may be relatively well tolerated in antiretroviral-experienced patients with high CD4 cell counts, provided there is no detectable plasma HIV viral load [34], which is also very common among coinfected patients beginning peg-IFN plus RBV treatment. Second, although the majority of episodes are mild and do not require discontinuation of the drug, NVP-based ART is associated with an increased risk of hepatotoxicity in HIV/HCV-coinfected patients $[35,36]$. Ultimately, the physician responsible for the patient should balance the potential benefit of NVP therapy on SVR with the risk of treatment-limiting toxicities associated with the use of this NNRTI, especially of acute liver toxicity.

In conclusion, antiretroviral drugs other than NRTI, specifically NVP, may influence the SVR rate to peg-IFN plus RBV treatment in HIV/HCV-coinfected patients. An association between NVP-based ART and low plasma HCV viral load may account for this finding. Therapy based on TDF plus 3TC or FTC along with NVP may be an optimized ART combination in coinfected individuals who are going to be treated against hepatitis $\mathrm{C}$. Controlled clinical trials are warranted in 
Citation: Mira JA, López-Cortés LF, Vispo E, Tural C, Laguno M, et al. (2010) Concomitant Nevirapine Therapy is Associated with Higher Efficacy of Pegylated Interferon Plus Ribavirin among HIV/Hepatitis C Virus-Coinfected Patients. J AIDS Clinic Res 1:112. doi:10.4172/2155-6113.1000112

order to determine the influence of NNRTIs and PIs on the efficacy of peg-IFN plus RBV-based combinations in the HIV-infected population.

\section{AThe VIRA-C STUDY GROUP}

Hospital Universitario de Valme, Sevilla (Macías J, Merchante N, Neukam K); Hospital Carlos III, Madrid (Barreiro P); Hospital Universitario de Bellvitge, Barcelona (Podzamczer D); Hospital de la Santa Creu i Sant Pau, Barcelona (Guardiola JM); Hospital Universitario Reina Sofía, Córdoba (Camacho A); Hospital Universitario Virgen Macarena (Ríos-Villegas MJ); Hospital Punta Europa, Algeciras (TorresTortosa M); Hospital Universitario Virgen de las Nieves, Granada (López-Ruz MA); Hospital Juan Ramón Jiménez, Huelva (Merino D); Hospital Universitario San Cecilio, Granada (Muñoz L); Hospital Universitario Virgen de la Victoria, Málaga (Márquez M, Ojeda G); Hospital Arquitecto Macide, Ferrol (Mariño A).

\section{Acknowledgements}

This study has been partly supported by grants from Boehringer Ingelheim Pharmaceuticals and the Consejería de Salud of the Junta de Andalucía, Spain (Reference: 0133/08). The authors wish to thank the Ministerio de Sanidad y Consumo, Instituto de Salud Carlos III, Red de SIDA from Spain for their support (ISCIII-RETIC RD06/006). Juan A. Pineda is the receptor of an intensification grant from the Consejería de Salud of the Junta de Andalusia (Reference: Al-0021).

\section{Refernces}

1. Pineda JA, Mira JA, de los Santos Gill, Valera-Bestard B, Rivero A, et al. (2007) Influence of antiretroviral therapy on the response to pegylated interferon plus ribavirin in hepatitis $\mathrm{C}$ virus/HIV-coinfected patients. J Antimicrob Chemother 60: $1347-1354$

2. García-Benayas T, Blanco B, Soriano V (2002) Weight loss in HIV-infected patients. N Engl J Med 347: 1287-1288.

3. Rockstroh JK, Bhagani S, Benhamou Y, Bruno R, Mauss S, et al. (2008) European AIDS Clinical Society (EACS) guidelines for the clinical management and treatment of chronic hepatitis B and C coinfection in HIV-infected adults. HIV Med 9: 82-88.

4. Panel de expertos de Gesida y Plan Nacional sobre el Sida (2010) AIDS Study Group/Spanish AIDS Plan consensus document on antiretroviral therapy in adults with human immunodeficiency virus infection. Enferm Infecc Microbiol Clin 28: 362.e1-91.

5. Bani-Sadr F, Carrat F, Pol S, Hor R, Rosenthal E, et al. (2005) Risk factors for symptomatic mitochondrial toxicity in HIV/hepatitis $\mathrm{C}$ virus-coinfected patients during interferon plus ribavirin-based therapy. J Acquir Immune Defic Syndr 40: 47-52.

6. Mira JA, López-Cortés LF, Merino D, Arizcorreta-Yarza A, Rivero A, et al. (2007) Predictors of severe hematological toxicity secondary to pegylated interferon plus ribavirin in HIV/HCV-coinfected patients. Antivir Ther 12: 1225-1235.

7. Mira JA, López-Cortés LF, Barreiro P, Tural C, Torres-Tortosa M et al. (2008) Efficacy of pegylated interferon plus ribavirin treatment in HIV/hepatitis $C$ viruscoinfected patients receiving abacavir plus lamivudine or tenofovir plus either lamivudine or emtricitabine as nucleoside analogue backbone. J Antimicrob Chemother 62: 1365-1373.

8. Vispo E, Barreiro P, Pineda JA, Mira JA, Maida I, et al. (2008) Low response to pegylated interferon plus ribavirin in HIV-infected patients with chronic hepatitis C treated with abacavir. Antivir Ther 13: 429-437.

9. Carrat F, Bani-Sadr F, Pol S, Rosenthal E, Lunel-Fabiani F, et al. (2004) Pegylated interferon alfa-2b, plus ribavirin, for chronic hepatitis $\mathrm{C}$ in HIVinfected patients. A randomized controlled trial. JAMA 292: 2839-2848.

10. Torriani FJ, Katlama C, Sulkowski M, Dore G, Cooper DA, et al. (2005) Sustained virological response to peginterferon alfa-2a (40KD) (PEGASYS) plus ribavirin (COPEGUS) in HIV-HCV co-infected patients according to antiretroviral therapy in the AIDS PEGASYS Ribavirin International Co-infection Trial (APRICOT). 10th European AIDS Conference. Dublin, Ireland. Abstract PE13.2/14.

11. Mira JA, López-Cortés LF, de los Santos Gil I, Torres-Tortosa M, Camacho A et al. (2009) Nevirapine-based antiretroviral therapy is associated with lower plasma HCV viral load in HIV/HCV-coinfected patients. 12th European AIDS Conference. Cologne, Germany. Abstract PE13.2/1.
12. Scheuer PJ (1991) Classification of chronic viral hepatitis: a need for reassessment. J Hepatol 13: 372-374.

13. Manns MP, McHutchison JG, Gordon SC, Rustgi VK, Shiffman M, et al. (2001) Peginterferon alfa-2b plus ribavirin compared with interferon alfa- $2 \mathrm{~b}$ plus ribavirin for initial treatment of chronic hepatitis $\mathrm{C}$ : a randomised trial. Lancet 358: 958-965.

14. Fried MW, Shiffamn ML, Reddy KR, Smith C, Marinos G, et al. (2002) Peginterferon alfa-2a plus ribavirin for chronic hepatitis $C$ virus infection. N Eng J Med 347: 975-982

15. Sánchez-Tapias JM, Diago M, Escartín P, Enríquez J, Romero-Gómez M, et al. (2006) Peginterferon-alfa2a plus ribavirin for 48 versus 72 weeks in patients with detectable hepatitis C virus RNA at week 4 of treatment. Gastroenterology 131: 451-460.

16. Torriani FJ, Rodríguez-Torres M, Rockstroh JK, Lissen E, Gonzalez-García J, et al. (2004) Peginterferon alfa-2a plus ribavirin for chronic hepatitis $C$ virus infection in HIV-infected patients. N Engl J Med 351: 438-450.

17. Laguno M, Cifuentes C, Murillas J, Veloso S, Larrousse M, et al. (2009) Randomized trial comparing pegylated interferon alpha- $2 b$ versus pegylated interferon alpha-2a, both plus ribavirin, to treat chronic hepatitis $C$ in human immunodeficiency virus patients. Hepatology 49: 22-31.

18. Fuster D, Planas R, González J, Force L, Cervantes M, et al. (2006) Results of a study of prolonging treatment with pegylated interferon-alpha2a plus ribavirin in HIV/HCV-coinfected patients with no early virological response. Antivir Ther 11: 473-482.

19. Bani-Sadr F, Goderel I, Morand P, Payan C, Lunel F, et al. (2007) High hepatitis $C$ virus load in HIV/hepatitis $C$ virus-co-infected patients: a different influence of protease inhibitor and non-protease inhibitor-based HAART?. AIDS 21: 16451648.

20. Dore GJ, Torriani FJ, Rodriguez-Torres M, Brau N, Sulkowski M, et al. (2007) Baseline factors prognostic of sustained virological response in patients with HIV-hepatitis C virus co-infection. AIDS 21: 1555-1559.

21. Daar ES, Lynn H, Donfield S, Gomperts E, Hilgartner MW, et al. (2001) Relation between HIV-1 and hepatitis $\mathrm{C}$ viral load in patients with hemophilia. J Acquir Immune Defic Syndr 26: 466-472.

22. Lin W, Weinberg EM, Tai AW, Peng LF, Brockman MA, et al. (2008) HIV increase HCV replication in a TGF-beta1-dependent manner. Gastroenterology 134 803-811.

23. Virgili N, Fisac C, Martínez E, Ribera E, Gatell JM, et al. (2009) Proinflamatory cytokine changes in clinically stable, virologically suppressed, HIV-infected patients switching from protease inhibitors to abacavir. J Acquir Immune Defic Syndr 50: 552-553.

24. Rohrbach J, Harcourt G, Gaudieri S, Robinson N, Telenti A, et al. (2009) Successful ART is associated with increasing HCV-specific $T$ cell responses. 16th Conference on Retroviruses and Opportunistic Infections. Montreal, Canada. Abstract 105

25. Tebas P, Yarasheski K, Henry K, Claxton S, Kane E, et al. (2004) Evaluation of the virological and metabolic effects of switching protease inhibitor combination antiretroviral therapy to nevirapine-based therapy for the treatment of HIV infection. AIDS Res Hum Retroviruses 20: 589-594.

26. Dai CY, Huang JF, Hsieh MY, Hou NJ, Lin ZY, et al. (2009) Insulin resistance predicts response to peginterferon-alpha/ribavirin combination therapy in chronic hepatitis C patients. J Hepatol 50: 712-718.

27. Conjeevaram HS, Kleiner DE, Everhart JE, Hoofnagie JH, Zacks S, et al. (2007) Race, insulin resistance and hepatic steatosis in chronic hepatitis C. Hepatology 45: 80-87.

28. Merchante N, de los Santos-Gil I, Merino D, González-Serrano M, Mira JA, e al. (2009) Insulin resistance is not a relevant predictor of sustained virological response to pegylated interferon plus ribavirin in HIV/HCV co-infected patients. J Hepatol 50: 684-692.

29. Cammà C, Petta S (2009) Insulin resistance in HCV mono-infected and in HIV/ HCV co-infected patients: Looking to the future. J Hepatol 50: 648-651.

30. Cacoub P, Carrat F, Bédossa P, Lambert J, Pénaranda G, et al. (2009) Insulin resistance impairs sustained virological response rate to pegylated interferon plus ribavirin in HIV-hepatitis C virus-coinfected patients: HOMAVIC-ANRS HC02 study. Antivir Ther 14: 839-845.

31. Romero-Gómez M, Diago M, Andrade RJ, Calleja JL, Salmerón J, et al. (2009) 
Citation: Mira JA, López-Cortés LF, Vispo E, Tural C, Laguno M, et al. (2010) Concomitant Nevirapine Therapy is Associated with Higher Efficacy of Pegylated Interferon Plus Ribavirin among HIV/Hepatitis C Virus-Coinfected Patients. J AIDS Clinic Res 1:112. doi:10.4172/2155-6113.1000112

Page 8 of 8

Treatment of insulin resistance with metformin in naïve genotype 1 chronic hepatitis $\mathrm{C}$ patients receiving peginterferon alfa-2a plus ribavirin. Hepatology 50: $1702-1708$.

32. Macias J, Mira JA, López-Cortés LF, Santos I, Girón-González JA, et al. (2006) Antiretroviral therapy based on protease inhibitors as a protective factor against liver fibrosis progression in patients with chronic hepatitis C. Antivir Ther 11 839-846.

33. Viramune (nevirapine). Prescribing information (2005) (USA). Ridgefield, CT: Boehringer Ingelheim Pharmaceuticals.
34. Kesselring AM, Wit FW, Sabin CA, Lundgren JD, Gill MJ, et al. (2009) Risk factors for treatment-limiting toxicities in patients starting nevirapine-containing antiretroviral therapy. AIDS 23: 1689-1699.

35. Sulkowski MS, Thomas DL, Mehta SH, Chaisson RE, Moore RD (2002) Hepatotoxicity associated with nevirapine or efavirenz-containing antiretroviral therapy: role of hepatitis $C$ and B infections. Hepatology 35: 182-189.

36. Rivero A, Mira JA, Pineda JA (2007) Liver toxicity induced by non-nucleoside reverse transcriptase inhibitors. J Antimicrob Chemother 59: 342-346. 